\title{
Influence of human footprint and sensory disturbances on night-time space use of an owl
}

\author{
C. A. Scobie ${ }^{1,3, *}$, E. M. Bayne ${ }^{1}$, T. I. Wellicome ${ }^{1,2}$ \\ ${ }^{1}$ Department of Biological Sciences, University of Alberta, Edmonton, Alberta T6G 2E9, Canada \\ ${ }^{2}$ Canadian Wildlife Service, Environment Canada, 925049 Street NW, Edmonton, Alberta T6B 1K5, Canada \\ ${ }^{3}$ Present address: Royal Alberta Museum, 12845102 Avenue, Edmonton, Alberta T5N 0M6, Canada
}

\begin{abstract}
Artificial sensory disturbances (sound and light) can extend far beyond the physical footprint of human development. Nocturnal predators such as owls may be influenced by artificial sound and light, as they depend on aural and visual cues when hunting. Owl nocturnal movements may also be altered by physical changes to the landscape, as these can affect prey availability. The burrowing owl population in Canada has declined by $90 \%$ and was classified as endangered in 1995. We tracked adult male burrowing owls Athene cunicularia with GPS dataloggers, and used resource selection models to examine their night-time movement patterns in relation to human infrastructure and associated artificial light and sound. The amount of sound and light from compressor stations, oil wells, traffic, towns and buildings was calculated for each owl and random location. We found that owl night-time space use was better predicted by distance to infrastructure on the landscape than by intensity of sensory disturbance. Burrowing owls did not show a pronounced avoidance of artificial sound. Infrastructure best predicts owl space use, perhaps because associated changes to vegetation alter prey abundance and availability. While human infrastructure most influenced owl nocturnal space use, the extent to which ecosystems are impacted by artificial sound and light is becoming clearer and needs to be considered when assessing the total effect of human development on species.
\end{abstract}

KEY WORDS: Sensory disturbance $\cdot$ Human development $\cdot$ Light $\cdot$ Sound $\cdot$ Resource selection · Burrowing owl $\cdot$ Athene cunicularia

\section{INTRODUCTION}

The greatest threat to native species from human development is habitat loss (Brooks et al. 2002, Fischer \& Lindenmayer 2007). However, an increasing body of evidence suggests that habitat degradation caused by anthropogenic sensory disturbances (e.g. noise and light) often exacerbates the direct effects of habitat loss by degrading the quality of the remaining habitat (Francis \& Barber 2013). Sensory disturbances affect a wide range of taxa (Longcore \& Rich 2004, Francis \& Barber 2013) and can alter a variety of breeding and foraging behaviours (Brumm 2004, Titulaer et al. 2012). In extreme cases, sensory

${ }^{*}$ Corresponding author: corey.scobie@gov.ab.ca disturbance has resulted in animals completely avoiding otherwise suitable habitat (Rotics et al. 2011, Blickley et al. 2012). Thus, if the impacts of sensory disturbances are not quantified, the cumulative area impacted by human developments may be underestimated.

It is challenging to separate the behavioural effects caused by the physical changes in vegetation structure and composition resulting from human development (hereafter, 'footprint') from those caused by sensory disturbances (hereafter, 'disturbance'). Studies evaluating the effects of noise on terrestrial wildlife typically have compared animal abundance or behaviour in the vicinity of quiet versus noisy roads, or

(C) The authors 2016. Open Access under Creative Commons by Attribution Licence. Use, distribution and reproduction are unrestricted. Authors and original publication must be credited. 
close to versus far from noisy roads. With such study designs, it is difficult to separate the effects of footprint from disturbance (Delgado et al. 2008, Summers et al. 2011), especially for wide-ranging species whose home ranges are influenced by multiple sensory disturbances. In these situations, it is difficult to use a noisy versus quiet or bright versus dark dichotomy when conducting analyses. Nonetheless, understanding how wide-ranging species, such as predators, react to disturbance is essential because they rely heavily on visual and auditory cues to detect and capture prey.

Sound emanating from anthropogenic sources has the potential to affect both predators and their prey. While travelling, prey may disturb vegetation, causing it to rustle, and rustling vegetation typically creates sound in frequencies above $1.6 \mathrm{kHz}$ (Miller 1978, Schomer \& Beck 2010). Many predators rely on sound in these high frequencies to detect, locate and capture small mammals (Payne 1971, Knudsen \& Konishi 1979, Singheiser et al. 2010). Mice select routes to minimize visibility and production of sound in these frequencies (Barnum et al. 1992) and in some situations travel on quieter substrates (Roche et al. 1999). Consequently, predators that use acoustic cues may avoid hunting in noisy areas if such noise affects their ability to detect the specific sounds made by moving prey (Hübner \& Wiegrebe 2003, Goerlitz et al. 2008, Siemers \& Schaub 2011). When noisier areas are not avoided, predators that rely on acoustic cues for hunting are less successful in capturing prey than when hunting in quieter areas (Schaub et al. 2008). Importantly, high frequency sounds travel shorter distances from the source than low frequency sounds (see ISO 1993), so the potential impact of anthropogenic sound on hunting may depend on which frequencies of sound are emitted.

Artificial light can affect circadian rhythms of animals at all times of the day, but the greatest impacts are typically on species that are active at night (Longcore \& Rich 2006, Gaston et al. 2013). The impact of artificial light on predators in particular is unclear. Nocturnal predators, such as owls, rely on both sight and sound when hunting (Dice 1945, Kaufman 1974), requiring a minimum level of light and acoustic cues to detect prey. Accordingly, most owls are more active (Penteriani et al. 2011, Frye \& Jageman 2012) and bring more prey back to their young (Poulin \& Todd 2006, Zárybnická et al. 2012), during crepuscular periods. Therefore, artificial light could actually benefit owls if it extends the period of time that they can see prey at night. Conversely, although light increases the detectability of prey, it could be detri- mental if prey availability decreases because prey remain closer to cover when it is brighter (Lockard \& Owings 1974, Kaufman \& Kaufman 1982, Clarke 1983, Wolfe \& Tan Summerlin 1989, Kotler et al. 1991, Daly et al. 1992). With increased illumination, prey move and forage less (Abramsky et al. 2004, Bird et al. 2004, Rotics et al. 2011), likely in response to increased predation risk (Clarke 1983, Kotler et al. 1991), so predators may need to search larger areas to find the same amount of prey under such conditions (Rockhill et al. 2013).

The effects of anthropogenic activities on predators that are hunting are often studied by tracking individuals as they travel through a landscape. However, few studies have attempted to separate the relative importance of footprint versus disturbance on predatory behaviour. Those studies that have attempted to do this (Chubbs et al. 1993, Jiang et al. 2010, Neumann et al. 2013) have typically been confounded because they rely on coarse categories of sensory disturbances (high versus low) rather than directly measuring the magnitude of sensory disturbances. Given the strong overlap in space and time of multiple disturbances in the 'disturbance landscape' for a wide-ranging predator, more precise measurement is needed to evaluate how disturbance levels alter predator behaviour.

Detailed measures of sensory disturbances are needed to evaluate the response of predator space use to artificial light and sound. Both light and sound are types of energy that move as waves through the air and decay as a function of distance. However, modelling only the distance to the nearest sound or light source will not accurately reflect resulting sound and light levels because of their differing physical properties and attenuations. Also, when sound or light from 2 sources spatially and temporally overlap, there is an increase in magnitude because of an additive effect, which is not captured by distance to source alone. Light waves are much smaller than sound waves, making them less susceptible to attenuation. Environmental conditions (wind, humidity, temperature, atmospheric pressure) and ground surface have a large effect on the propagation of sound waves, but those factors do not affect light as it travels from a source. The intensity of sound and light emanating from human structures can be quite diverse, resulting in a landscape with spatially and temporally varying sound and light levels. This is the first study to consider these factors and develop detailed measures of light and sound in an effort to examine space use of a nocturnal predator in relation to artificial sensory disturbances. 
To study the influence of both light and sound on the space use of a predator that relies on both auditory and ocular cues while hunting, nocturnal movement patterns must be quantified. Burrowing owls occur throughout North and South America and the IUCN lists the entire population ( $\geq 15$ subspecies) as Least Concern due to its large range (BirdLife International 2012). The Western burrowing owl Athene cunicularia hypugaea in Canada was classified as endangered in 1995 (Wellicome \& Haug 1995), where it has declined by $90 \%$, resulting in less than 800 breeding pairs (Environment Canada 2012). Portions of Canada's grasslands have been developed significantly, forcing burrowing owls to live in landscapes with varying levels of anthropogenic light and sound. Burrowing owls capture the majority of their prey during twilight (Poulin \& Todd 2006); however, they do not have asymmetrical ears (Volman \& Konishi 1990) to help them effectively locate prey by sound, so they cannot capture prey in very low light conditions like owls that do have asymmetrical ears (Dice 1945). Thus, burrowing owls rely on both hearing and sight to detect prey. If owl movement patterns are influenced by artificial light and sound, that influence will be most pronounced during twilight hours when owls are moving most and the largest number of prey are brought back to the nest (Poulin \& Todd 2006).

To examine the night-time movement patterns of a predator in relation to human infrastructure and associated artificial light and sound, we tracked the nocturnal foraging of adult male burrowing owls wearing GPS dataloggers under 2 temporal periods (twilight and night). If owl nocturnal space use is influenced most by sensory disturbance associated with human development, then models containing only those variables will fit best. If the best models contain variables relating to the footprint, then owls are likely more affected by the physical landscape changes that result from human development. If these disturbances are sufficient to alter hunting behaviour, we predict that male owls will be most influenced by sensory disturbances during twilight hours and will select areas with lower sound levels in high sound frequencies and lower levels of artificial light to enable effective detection of prey in areas where prey availability is greatest.

\section{MATERIALS AND METHODS}

Between 2007 and 2010, we monitored 521 burrowing owl nesting attempts within the dry mixed-grass ecoregion of southern Alberta and Saskatchewan, Canada, where cattle ranching and annual crop production are the primary land uses. Petroleum development also occurs throughout the study area in Alberta and in localized areas in Saskatchewan. Within the burrowing owl range in Alberta and Saskatchewan $\left(\sim 177000 \mathrm{~km}^{2}\right)$, there are over 190000 gas wells, 160000 oil wells (IHS Energy 2011c), 1600 compressor stations and other petroleum facilities that pro-

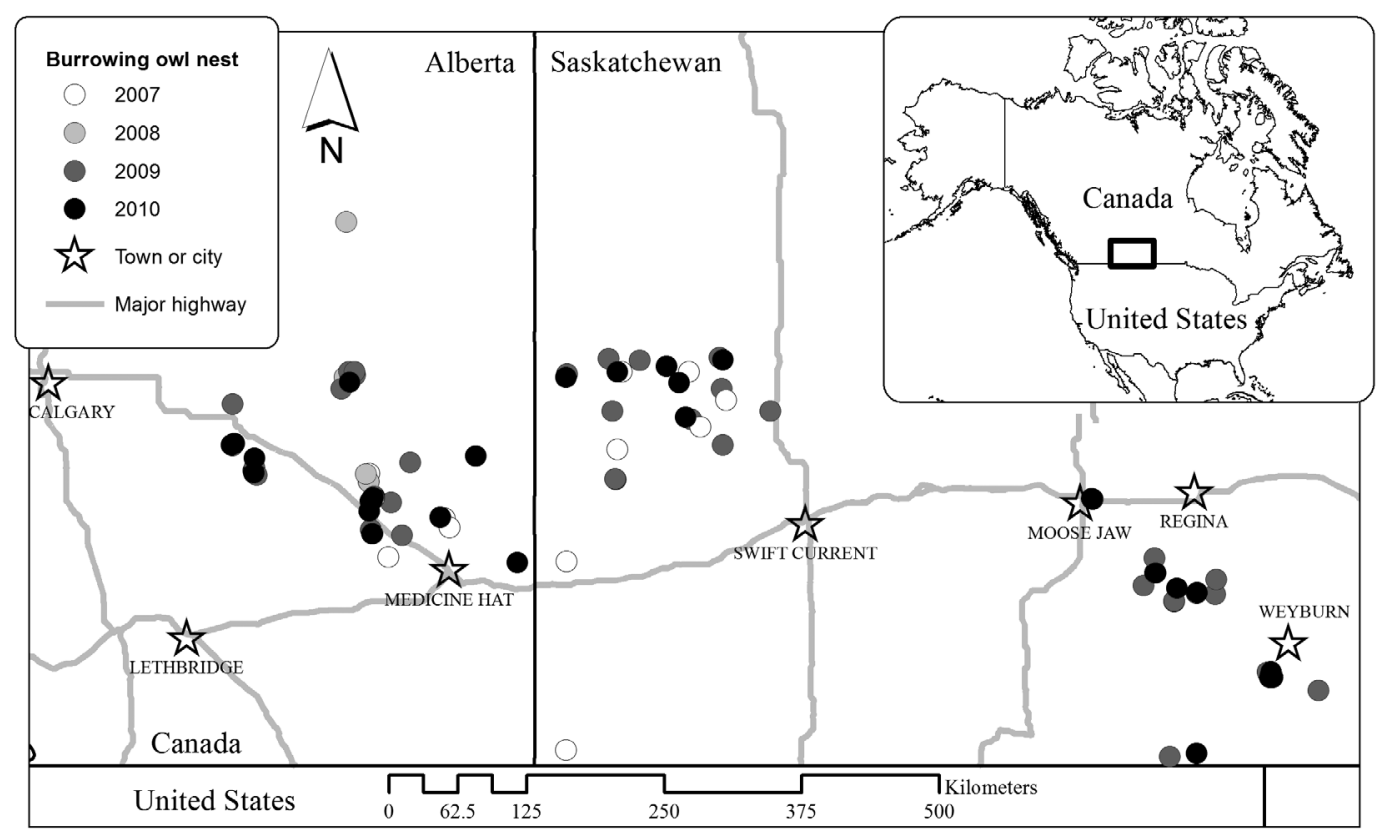

Fig. 1. Locations of burrowing owl Athene cunicularia nests from which each adult male was tracked with a GPS datalogger 
duce sound (IHS Energy 2011a), over $20000 \mathrm{~km}$ of paved roads (IHS Energy 2011b) and approximately 500000 people that live in 24 urban areas (Statistics Canada 2012). Less than $30 \%$ of the grasslands in Alberta, Saskatchewan and Manitoba remain uncultivated (Gauthier \& Wiken 2003).

At a subset of the burrowing owl nesting attempts monitored, 84 adult males were tracked with GPS dataloggers (Fig. 1). Nests were located in early May using call play-back surveys, and were visited once per week throughout the breeding season (see Fisher et al. 2015 for additional details). After the female finished laying, and before juveniles fledged, each adult male owl was captured with either a 1-way walk-in (Winchell 1999) or bow-net trap (Bloom 1987). During these stages in nesting, the male delivers over $80 \%$ of the prey to the nest (Poulin \& Todd 2006) and thus travels more and farther from the nest than the female. Therefore, tracking the male will give us the greatest ability to detect whether landscape features or sensory disturbances influence where owls spend their time while hunting. Each trap had 1 of the following lures: (1) a dead mouse, (2) a speaker playing a burrowing owl primary call, (3) a decoy burrowing owl, or (4) some combination of these 3 lures. A $7 \mathrm{~g}$ GPS datalogger (TechnoSmArt, Guidonia Montecelio) was attached to each owl, using Teflon ribbon in a backpack-style configuration. Teflon was secured to the datalogger with light-weight packing tape containing a tear-proof fibreglass cross-weave. Males were returned to their nest burrows for release after dataloggers were attached. The dataloggers were upgraded by the manufacturer each year, resulting in varying options and program schedules over time. Dataloggers were programmed to turn on and take locations every $2 \mathrm{~s}$ (2009 and 2010), every $15 \mathrm{~min}$ $(2007,2009,2010)$, or every hour (2008). The following data were stored in the internal memory within the GPS datalogger: latitude, longitude, speed, altitude, dilution of precision, Greenwich Mean Time and date. To retrieve the data, each owl was re-trapped after approximately $12 \mathrm{~d}$, by which time its GPS datalogger battery had been depleted. Owl locations with dilution of precision $>1.5$, speed $>64 \mathrm{~km} \mathrm{~h}^{-1}$, and altitude $\leq 20 \mathrm{~m}$ below and $\geq 80 \mathrm{~m}$ above the elevation of the owl's nest were excluded. One location every $15 \mathrm{~min}(2007,2009,2010)$, or else 1 location every hour (2008), was selected for these analyses. The accuracy of the GPS dataloggers was tested by measuring the distance between locations from a stationary GPS datalogger placed on a fence post for $3 \mathrm{~d}$ and the stationary datalogger's location as determined with the averaging function in a hand-held GPS unit. All data were collected by trained field staff in possession of valid animal care approval, federal and provincial research permits and bird banding licenses (permit number 10796).

Burrowing owl GPS datalogger locations were used to examine owl foraging areas and movement patterns. For each owl, we delineated the average hourly step length (distance between successive owl locations) area of the $100 \%$ minimum convex polygon and for each night tracked using ArcMap 10.1 (ESRI) and Geospatial Modelling Environment (Beyer 2012). Average step length and distance to nest were calculated for each owl for each hour of the night. Each year, land-cover surrounding the nest of each tracked owl was documented by driving the roads around the nest and recording the land-cover types on aerial photographs. These aerial photographs were digitized in a GIS environment onto SPOT5 imagery (2006 coverage). Land-cover types (permanent cover [native and tame grassland], annual crop, riparian area [sparse vegetation and seasonally dry], road, water bodies [standing water all year], buildings [residential and agricultural buildings], shrubs and trees) were all included in statistical models, with permanent cover being the reference category.

We included in our analyses owl locations taken between nautical twilight start and end, to ensure that we used only locations from nocturnal foraging activities (Poulin \& Todd 2006). Owl prey delivery rates vary considerably between the twilight and night period (Poulin \& Todd 2006), so locations in these 2 periods were analysed separately. All locations between sunset and sunrise were categorized as night locations, and all remaining locations that occurred between night and nautical twilight start and night and nautical twilight end were categorized as twilight locations. Sun position times were determined from the National Research Council Canada website (www.nrc-cnrc.gc.ca/eng/services/sunrise/ advanced.html) using the coordinates of the nests.

Prior to analyses, all data were evaluated for colinearity among covariates. When co-linearity was detected, the variable with the highest variation inflation factor (VIF) was removed and the VIF was then recalculated for each variable. This was repeated until all VIFs were $<3$ (Quinn \& Keough 2002).

'Available' area was defined as a radius around the nest equal to the maximum distance that an individual owl travelled during the period it was tracked (Glenn et al. 2004). Using this area as available allows an examination of the factors that influenced where owls placed their foraging areas in relation to their nest burrows. This is the best way to detect avoidance 
of areas near the nest. For each owl location, 5 random locations were generated within the available area. Land-cover, sound, light (2009 Defense Meteorological Satellite Program average light images [Data collected by the US Air Force Weather Agency and processed by NOAA's National Centers for Environmental Information; http://ngdc.noaa.gov/eog/dmsp/ downloadV4composites.html), and distance to nest burrow, nearest compressor station, oil well, paved road, building and town were determined for each owl datalogger location and each random location. The Defense Meteorological Satellite Program average stable light images for 2009 were used to determine the amount of artificial light at each owl and random location. These images are based on data collected by the US Air Force Weather Agency and Processed by the National Oceanic and Atmospheric Administration National Geophysical Data Center (now the National Centers for Environmental Information). Pixels in the image were given values of 0 if they contained ephemeral light or no light, whereas cities, towns and other sites with persistent light contained values ranging from 1 to 63, depending on the intensity of light in that pixel. Distances to the nearest compressor station, paved road and oil well were limited to features that were within a radius equal to the available area plus $5 \mathrm{~km}$. Features within these spatial limits were used because that area includes all of the sound sources used to calculate the sound pressure level at each datalogger and random location. Also, it is possible that light from features outside the available area extend into the available area, so we wanted to ensure that these light sources were included in the footprint models. The model for each owl contained all covariates with VIFs $<3$.

We used resource selection functions (RSFs) to examine owl space use in relation to human infrastructure and in relation to the light and sound emanating from this infrastructure. To understand if the sensory disturbance or the footprint of human development most strongly influenced owl night-time movements, 3 models (baseline, disturbance and footprint) were compared for both nocturnal periods (twilight and night). The baseline model contained land cover and distance to the nest burrow. The disturbance model contained land cover, distance to nest burrow, light, and sound. The footprint model contained land cover, distance to nest burrow, and the nearest distance to each feature from which either sound or light emanates (compressor station, oil well, paved road, town and human building). Distance to each of these landscape features was used because sound emanates from compressor stations, oil wells and high traffic-volume roads and light emanates from compressor stations, cars driving on paved roads and towns and buildings (e.g. farm yards, agricultural buildings, etc.). Sound and light levels are not perfectly correlated with distance to sound and light sources because each source has different levels of light and sound that are subject to differing sources of attenuation, and sound and light can combine to produce areas with higher disturbance levels.

The 3 models (baseline, disturbance and footprint) were compared only for owls with exposure to artificial light or sound in the disturbance model and if all 3 models converged. A generalized linear model with a binomial error and logit link was used to analyse the data for each owl. Random locations were given one-fifth the weight of the datalogger locations of used points when computing statistical significance (see Aldridge \& Boyce 2007). A 2-step approach was employed, whereby the coefficients and standard errors from the model for each owl were used to calculate the inverse variance weighted mean (Nielsen et al. 2009), standard error, $z$-value and p-value for each covariate. A generalized linear mixed model (with each owl as the random variable) was also used to determine owl selection within the available area. Models with the lowest Akaike's information criterion (AIC; Burnham \& Anderson 2002) were identified as the best fitting models. The negative regression coefficients are presented for distance variables so that the response of the owl (selected versus avoided) matched the signs (positive versus negative) of the coefficients for the other variables.

\section{Sound}

The number of decibels above that which can be detected by an owl was determined for each onethird octave band for each owl and random location. Following the protocol outlined in ISO 8297 (ISO 1994), sound was measured with a handheld Brüel \& Kjær Type 2250 sound level meter at all compressor stations within the available area plus $5 \mathrm{~km}$. Sound from individual oil wells does not vary significantly, so following ISO 3746 (ISO 2010), sound was measured at a subset of each type of sound-producing oil well (pump jacks and screw pumps). The equivalent continuous $\left(\mathrm{LZ}_{\text {eq }}\right)$ sound power level was then calculated for each one-third octave band between 0.5 and $10 \mathrm{kHz}$ for each sound source, using the calculations provided in each corresponding standard. The average sound power level of all oil wells for each one- 


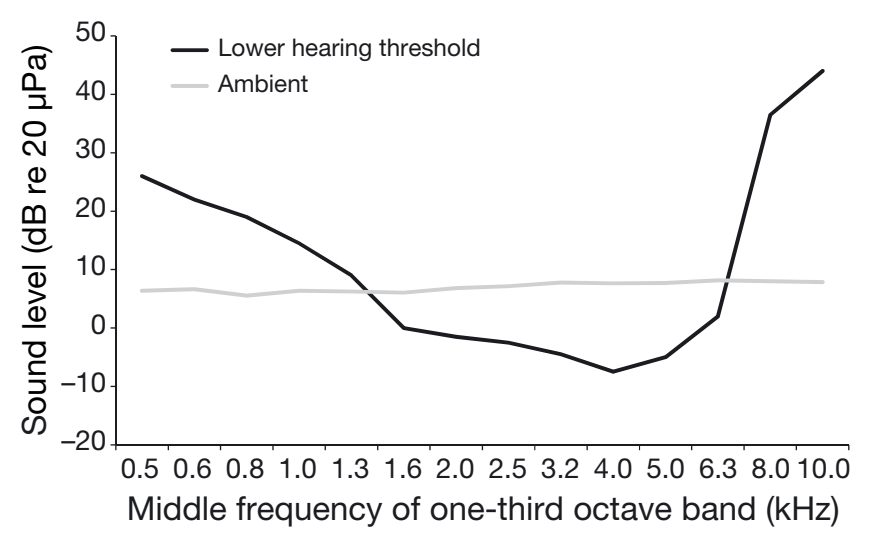

Fig. 2. Lower hearing threshold of eastern screech owls Megascops asio (adapted from Brittan-Powell et al. 2005) and ambient sound level for each one-third octave band from 0.5 to $10 \mathrm{kHz}$. Owls can hear sounds that are louder than ambient sound or are above their lower hearing threshold

third octave band was used when modelling sound propagation from each oil well. During each day of sound data collection in the field, ambient sound $\left(\mathrm{L}_{\mathrm{eq}}(1 \mathrm{~min})\right)$ was measured at locations at least $5 \mathrm{~km}$ away from sound-producing structures. All of our ambient sound measurements were taken during the day, so the lowest sound pressure level of all ambient sound measurements for each one-third octave band was used as the night-time ambient sound pressure level (Fig. 2). The sound level meter was calibrated with a Brüel \& Kjær sound level calibrator type 4231 at the beginning of each day prior to the collection of sound measurements.

Traffic data were collected from 15 roads that ran near owl nests in our study. Pneumatic tube traffic counters (MetroCount; MC5600 Series Roadside Unit) were deployed on 9 roads, traffic data for 4 roads were provided by the Saskatchewan Ministry of Highways and Infrastructure, and data for 2 roads were provided by the Alberta Ministry of Transportation. The pneumatic tube traffic counters recorded the date, time, speed and class of each vehicle that passed. Data provided by the provinces contained average hourly traffic volume, speed and proportion of heavy vehicles for each day. All data were collected for dates during the summer within $1 \mathrm{yr}$ of the owl being tracked. Individual vehicle hits recorded on the traffic counters were used to calculate average traffic volume, speed, and percent heavy vehicles for each hour the owls were tracked (sunset to sunrise). Vehicles were considered heavy if they were in the fourth weight class or greater according to the Federal Highway Administration (2013).

Average hourly continuous energy equivalent sound power level of traffic (herein average traffic sound) was calculated for roads within the available area plus $5 \mathrm{~km}$. Hourly traffic volume, speed and proportion of heavy vehicles were used to calculate energy equivalent sound level for each hour $\left(\mathrm{L}_{\mathrm{eq}}(1 \mathrm{~h})\right)$ for each road (using Besnard et al. 2009). Only roads with at least 20 vehicles $\mathrm{h}^{-1}$, for at least $1 \mathrm{~h}$ during the nocturnal period, were included. Traffic volumes $<20$ vehicles $\mathrm{h}^{-1}$ produce infrequent sensory disturbance and would not likely affect owl movement patterns at a scale detectable by the frequency of our owl locations. For the same reason, average traffic sound was used instead of the instantaneous sound from the loudest vehicle $\left(\mathrm{L}_{\mathrm{eq}}(\max )\right)$ that passed each hour.

Sound propagation and attenuation, from sound sources to each owl and random location, were calculated using the international standards ISO 9613-1 (ISO 1993) and 9613-2 (ISO 1996). Sound was modelled from each compressor station and each road with $\geq 20$ vehicles $h^{-1}$, and from the nearest 10 oil wells, to each owl location and each random location. For calculating the attenuation of sound due to atmospheric interference, 5 random locations were randomly matched with 1 owl location by assigning the same above-ground height, date and time as was recorded at the corresponding owl location. Characteristics of the tallest hill (Natural Resources Canada 2000) blocking the line of sight between the sound source and receiver (owl or random location) were used to calculate attenuation from screening. Hourly temperature, humidity and atmospheric pressure from the nearest Environment Canada weather station (http://climate.weather.gc.ca/index_e.html\#access) were used to calculate the atmospheric attenuation coefficient for each owl and random location. ArcMap 10.1 (ESRI) was used to extract all other cartographical variables needed for attenuation calculations. The sound pressure levels from all sources were then added together for each owl and random location.

\section{Owl detection of sound}

To adjust differences in hearing sensitivities, the minimum sound level that an animal can detect in each frequency can be extracted from lower hearing threshold audiograms and be used in sound detection calculations to better reflect how a species perceives sound (Pater et al. 2009). A burrowing owl audiogram was not available, but they have symmetrical ears and hunt similar prey to that of eastern screech owls Megascops asio, so the auditory brainstem response for the latter species (Brittan-Powell et al. 2005) was converted to a behavioural lower hear- 
ing threshold by subtracting $30 \mathrm{~dB}$ from the sound pressure level in each one-third octave band (BrittanPowell et al. 2002).

Sound from the source(s) was detectable at the receiver location (owl or random location) if the sound pressure level was above ambient sound levels when ambient sound was above the lower hearing threshold (Fig. 2). If ambient sound was below the lower hearing threshold, then sound was detectable if the sound pressure level from the source(s) was greater than the lower hearing threshold. These criteria were then used to calculate the number of decibels that could be detected at the receiver location for each one-third octave band. A value of 0 was assigned if no sound could be detected.

Eastern screech owls hear best in the $4 \mathrm{kHz}$ onethird octave band (Brittan-Powell et al. 2005), but have similar abilities to detect sounds between 1.6 and $6.3 \mathrm{kHz}$ when masking from ambient sounds is also considered (Fig. 2). The sound levels were highly correlated for all frequencies, so the frequency with the highest VIF was selected. The one-third octave band with the highest VIF was $2.5 \mathrm{kHz}$.

The distance from which burrowing owls can still detect sound from each source (i.e. the listening area; see Barber et al. 2010) in each one-third octave band from 0.5 to $10 \mathrm{kHz}$ was calculated. The average sound power level of each sound source (Fig. 3) and the formulae from international standards 9613-1 (ISO 1993) and 9613-2 (ISO 1996) were used to calculate sound propagation and attenuation under the average nighttime environmental conditions experienced by owls while they were being tracked. The calculations as-

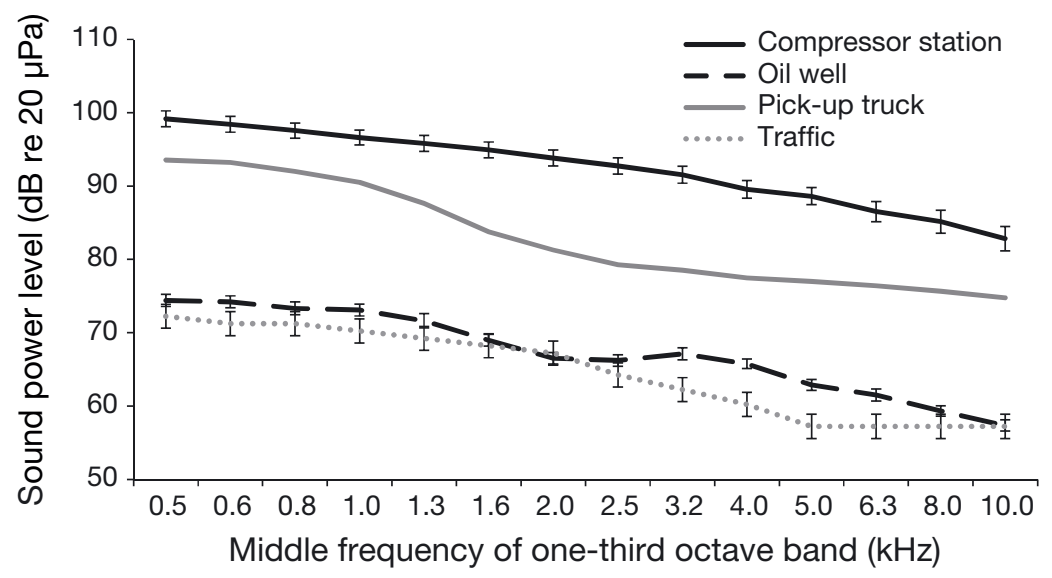

Fig. 3. Average sound power level of 38 compressor stations, 44 oil wells (35 pump jacks and 9 screw pumps combined), average hourly continuous energy equivalent sound power level of traffic $\left(\mathrm{L}_{\mathrm{eq}}(1 \mathrm{~h})\right)$ on 14 roads and the average maximum instantaneous sound power level $\left(\mathrm{L}_{\max }\right)$ of a half-tonne pick-up truck travelling $97 \mathrm{~km} \mathrm{~h}^{-1}$ on a gravel road for each one-third octave band from 0.5 to $10 \mathrm{kHz}$. Error bars are $95 \%$ confidence intervals sumed no barriers, and that there was grassland between sound source and receiver, and that wind speed was negligible. Owl detection of sound was determined using the same criteria outlined above.

\section{Home range size}

We also used linear regression to examine the relationship between the total area within each owl's nocturnal home range and the area within the home range that was exposed to artificial light and sound in the $2.5 \mathrm{kHz}$ one-third octave band. Prior to analysis, light and sound were log-transformed because they each contained outliers, and we also modelled these variables as categorical variables (present in homerange $=1$, absent $=0$ ). All models contained the number of nights tracked as a covariate, and we used AIC to select the form of the sensory disturbance variable that best fit the data.

\section{RESULTS}

We tracked 84 male owls for an average $( \pm \mathrm{SE}$, unless otherwise noted) of $3.7 \pm 0.33$ nights (range: 1-10) per owl. All owls were tracked between 17 May and 19 July. From these owls, we acquired a total of 8760 locations, with an average of $104 \pm 9.7$ locations (7-332) per owl. The GPS dataloggers were successful in obtaining fixes $96 \%$ of the time $(74-100 \%)$. Locations from the stationary test-datalogger were an average of $4.3 \pm 2.9 \mathrm{~m}$ (SD) from the test location, with a dilution of precision $\leq 1.5$. While owls were being tracked, average hourly humidity was $76.5 \pm 5.11 \%$, temperature was $11.7 \pm 1.31^{\circ} \mathrm{C}$, atmospheric pressure was $93.1 \pm 0.32 \mathrm{kPa}$, and wind speed was $3.3 \pm 0.64 \mathrm{~km} \mathrm{~h}^{-1}$.

Owl step length and $100 \%$ minimum convex polygon were smaller in the first full night after datalogger attachment than in the remaining tracking nights, so owl locations from the first full night were excluded from the analyses. This left 6196 locations from 63 owls, over an average of $4.7 \pm 0.38$ nights, with an average of $98 \pm 10.92$ locations per owl.

We measured sound at 38 compressor stations and 44 oil wells (35 pump jacks and 9 screw pumps), and took 21 ambient sound measurements. Sound 


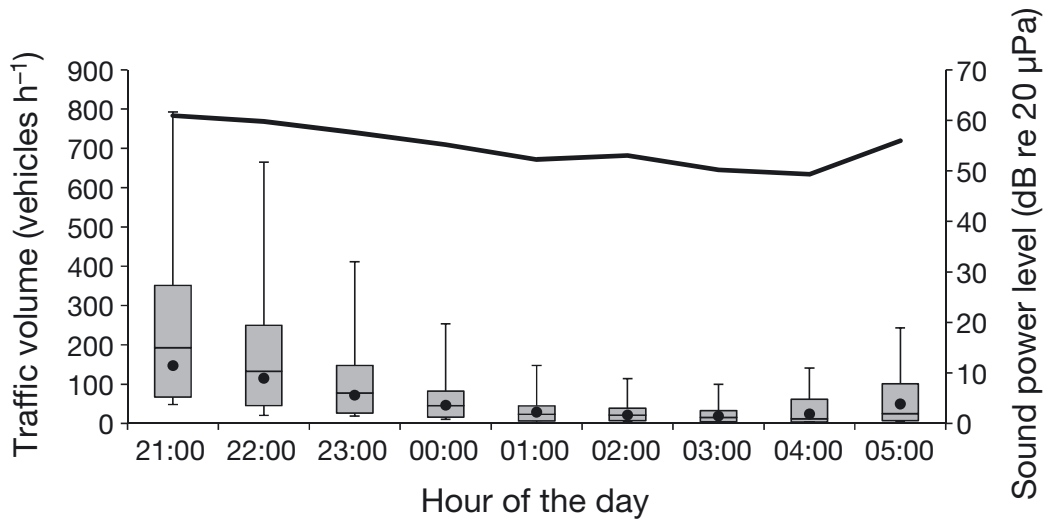

Fig. 4. Hourly traffic volume (box plots) and average hourly continuous energy equivalent sound power level (solid line) of traffic (in $2.5 \mathrm{kHz}$ one-third octave band) on 14 paved roads near burrowing owl Athene cunicularia nests where owls were tracked with GPS dataloggers. Upper limit of a box plot is the third quartile; middle line is the median; lower limit of the box is the first quartile; whiskers represent minimum and maximum values, and the black dot is the average

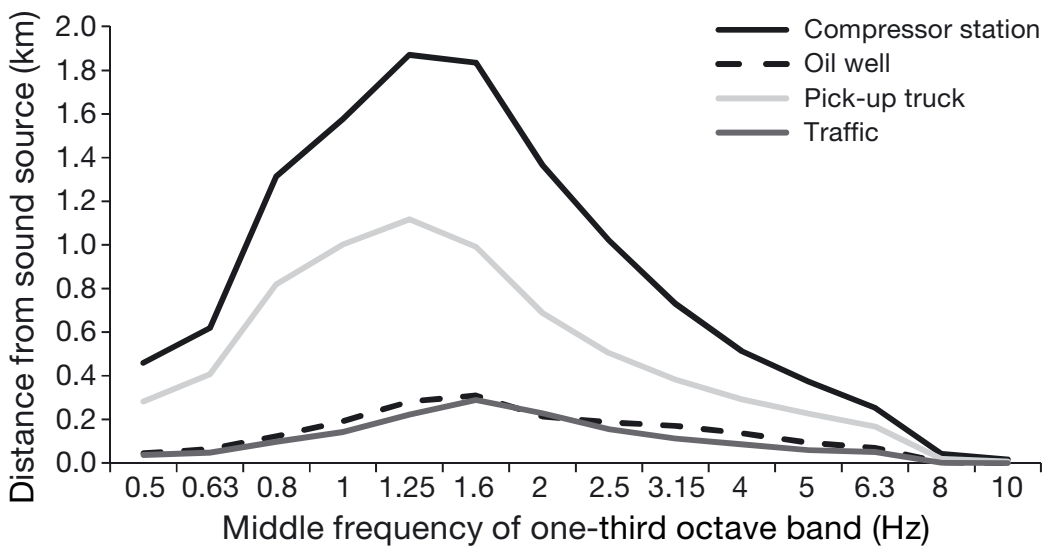

Fig. 5. Distance at which a burrowing owl Athene cunicularia can detect each of 4 sound sources in the $2.5 \mathrm{kHz}$ one-third octave bands. Sound levels used in the calculations were the average sound power levels of compressor stations and oil wells. For traffic, the average continuous energy equivalent sound power levels were calculated across all hours for traffic for each road, and then averaged for all roads. The sound level used for the pick-up truck calculations was the average instantaneous sound power level of a half tonne pick-up truck travelling at $97 \mathrm{~km} \mathrm{~h}^{-1}$ on a gravel road. Calculations assume that there are no barriers between source and receiver (owl) and that wind is negligible

level on these roads in the $2.5 \mathrm{kHz}$ one-third octave band was $64.24 \mathrm{~dB}$ (55.6-72.9 dB). Compared to the sound power levels of oil wells and compressor stations, average traffic sound was low, especially in the high sound frequencies, primarily because of low traffic volumes (<100 vehicles $\mathrm{h}^{-1}$ for all hours except 21:00 and 22:00 h, Fig. 4). The average speed of vehicles travelling at night was $97 \mathrm{~km} \mathrm{~h}^{-1}$. The maximum sound power level ( $\left.\mathrm{L}_{\mathrm{eq}}(\max )\right)$ of a pickup truck travelling at $97 \mathrm{~km}$ $\mathrm{h}^{-1}$ is $79.3 \mathrm{~dB}$ in the $2.5 \mathrm{kHz}$ one-third octave band.

Owls are likely able to detect sound in the $2.5 \mathrm{kHz}$ one-third octave band up to 1020, 187, 156 and $504 \mathrm{~m}$ from compressor stations, oil wells, traffic and a passing pickup truck driving at $97 \mathrm{~km} \mathrm{~h}^{-1}$, respectively, but they can hear sound in the 1.25 or $1.6 \mathrm{kHz}$ onethird octave band from all of these sources the farthest (Fig. 5). This is because owls hear best in higher frequencies (i.e. $4 \mathrm{kHz}$ ), but sound in high frequencies are affected more by atmospheric attenuation, and therefore do not travel far from the source. The sound levels produced by these sources are also greater in the low frequencies (Fig. 3), and owl hearing ability declines dramatically in frequencies lower than $1.25 \mathrm{kHz}$ (Fig. 2).

On average, $3.2 \pm 0.01 \%(0-26.7 \%)$ of the home range contained sound audible to owls in the $2.5 \mathrm{kHz}$ onethird octave band and $19.4 \pm 0.03 \%$ (0-100\%) contained artificial light. We found no significant relationship be-

power levels for all sound sources were greatest in the lower frequencies (Fig. 3). On average, there were 2 compressor stations (0-11) and 31 oil wells (0-346) within the burrowing owl available area.

Average traffic sound was calculated for 14 paved roads that passed near the nest burrows of 29 owls tracked with dataloggers. The average hourly vehicle speed was $96.9 \mathrm{~km} \mathrm{~h}^{-1}\left(91-100 \mathrm{~km} \mathrm{~h}^{-1}\right)$, average hourly proportion of heavy vehicles was 0.21 (0.150.38), and average hourly traffic volume was 58.0 vehicles $\mathrm{h}^{-1}$ (range of averages: 19.0-146.8; Fig. 4). These roads were, on average, $4.58 \mathrm{~km}$ (0.04$10.12 \mathrm{~km}$ ) from a nest. The average sound power tween owl home-range sizes and amount of artificial light or sound in the $2.5 \mathrm{kHz}$ one-third octave band.

During both night-time and twilight, the footprint RSF models were better predictors of resource selection than the disturbance or baseline models (Fig. 6). The footprint model was also better for the generalized linear mixed models (GLMMs) (Table 1). Models containing sensory disturbance variables were the best models during the twilight hours for $39 \%$ of owls (Fig. 6).

The inverse variance weighted (IVW) mean and GLMM RSF coefficients indicate that owls were weakly attracted to areas with higher sound levels in 


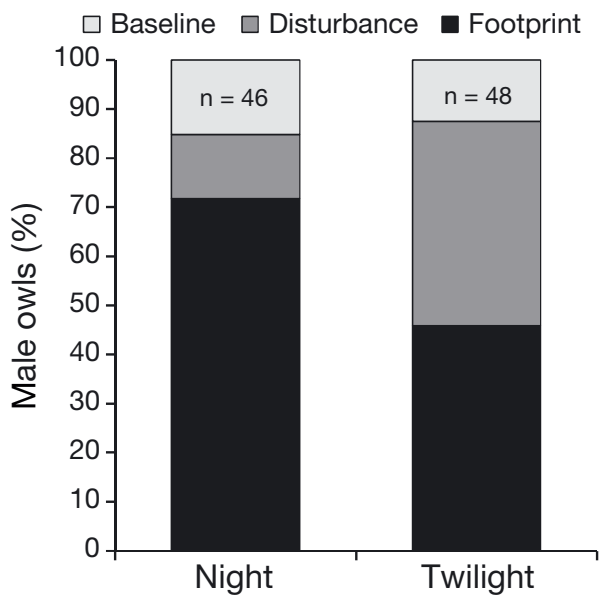

Fig. 6. Percent of burrowing owls Athene cunicularia with the baseline, disturbance or footprint model as the best resource selection function (RSF) model. The baseline model contained land cover and distance to the nest burrow; the disturbance model contained land cover, distance to nest burrow, light and sound; and the footprint model contained land cover, distance to nest burrow and the nearest distance to each feature from which either sound or light emanates (compressor station, oil well, paved road, town, building). During both night and twilight, the footprint models were the best predictors of selection

the $2.5 \mathrm{kHz}$ one-third octave band, but only about half of the owls had a positive RSF coefficient (Fig. 7). Although there is only about a $15 \%$ difference between the number of owls avoiding sound during night versus twilight, more owls were avoiding higher audible sound during twilight hours (Fig. 7). At night, 18 owls showed selection for areas with higher sound levels (Fig. 7), but only 7 showed statistically significant attraction $(p<0.05)$. Each of these 7 owls was also sig-

Table 1. Comparison of burrowing owl Athene cunicularia generalized linear mixed models (GLMM) resource selection functions (RSF) using Akaike's information criterion (AIC). Baseline model contained land cover and distance to the nest burrow; disturbance model contained land cover, distance to nest burrow, light and sound; footprint model contained land cover, distance to nest burrow and the nearest distance to each feature from which either sound or light emanates (compressor station, oil well, paved road, town,

building). $k$ is the number of parameters in the model

\begin{tabular}{|lccc|}
\hline Model & $k$ & AIC & $\Delta$ AIC \\
\hline Twilight & & & \\
Footprint & 14 & 29386 & 0 \\
Disturbance & 12 & 29818 & 433 \\
Baseline & 9 & 30052 & 667 \\
Night & & & \\
Footprint & 14 & 27945 & 0 \\
Disturbance & 12 & 28964 & 1018 \\
Baseline & 9 & 29529 & 1584 \\
\hline
\end{tabular}

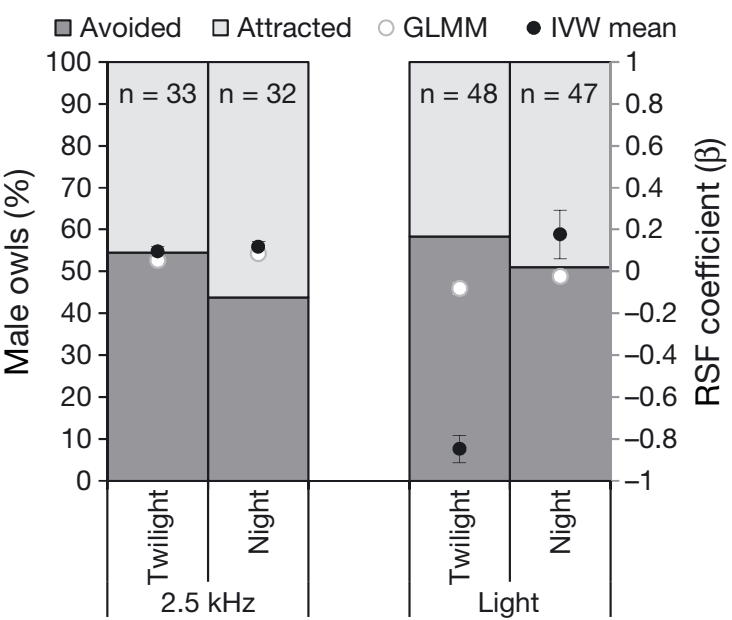

Fig. 7. Percent of male burrowing owls Athene cunicularia attracted to $(\beta>0)$ or avoiding $(\beta<0)$ sound $(2.5 \mathrm{kHz})$ and light and the inverse variance weighted (IVW) mean and generalized linear mixed model (GLMM) resource selection function (RSF) coefficients ( $\beta$ ). Bars are related to the left $y$ axis; circles and error bars are related to the right $y$-axis.

Error bars are $95 \%$ confidence intervals

nificantly attracted to at least 1 of the soundproducing structures in the footprint models. In addition, the footprint model was the best fitting for 5 of those 7 owls. During twilight hours, 15 owls showed selection for areas with higher sound levels (Fig. 7), but only 5 significantly so. Four of these 5 owls were significantly attracted to at least 1 sound-producing structure, and the footprint model fit best for all 5 .

Significance between RSF coefficients in the IVW mean and GLMM models for light differed from each other, but followed a similar trend where there were smaller values (increased avoidance) during twilight hours and larger values (increased selection) during night-time hours (Fig. 7).

There was less agreement between the IVW means and GLMM RSF coefficients for distance to nearest facility and oil well, although most owls are attracted to these features during both twilight and night-time (Fig. 8). Though not always significant, the IVW mean RSF coefficients showed more attraction to these features during the night than during twilight hours (Fig. 8). All RSF coefficients showed that owls were significantly attracted to paved roads in both time periods (Fig. 8).

\section{DISCUSSION}

Owl night-time space use was better predicted by distance to infrastructure on the landscape than by degree of sensory disturbance. The best model for 


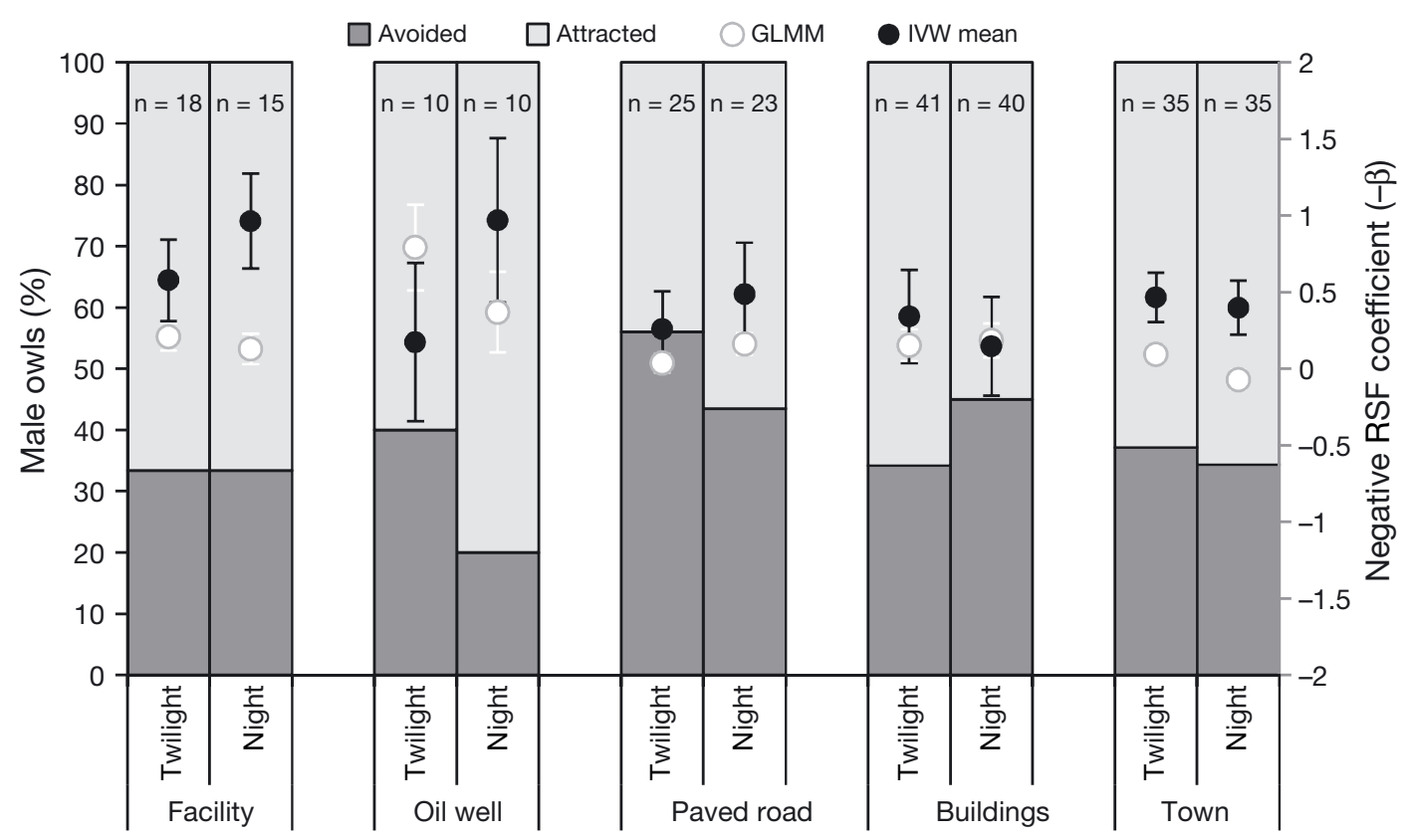

Fig. 8. Percent of male burrowing owls Athene cunicularia attracted to $(-\beta>0)$ or avoiding $(-\beta<0)$ compressor stations, oil wells, paved roads, buildings and towns and the inverse variance weighted (IVW) mean and generalized linear mixed model $(G L M M)$ resource selection function (RSF) coefficients $(-\beta)$. This figure shows variables that were the distance to the nearest feature, so the negative of the RSF coefficient is presented such that the direction of the sign (positive vs. negative) corresponds to owl response to the feature (attracted vs. avoided). Bars are related to the left $y$-axis; circles and error bars are related to the right $y$-axis. Error bars are $95 \%$ confidence intervals

the majority of owls, and mixed effect models, contained distance to nearest human structures, and not variables related to the sound and light that these human structures emit. This differed from our predictions that owl nocturnal space use would be most influenced by anthropogenic sound and light levels. Owls rely on auditory and visual cues when hunting at night, but our analysis indicates that their nighttime movement patterns were better predicted by changes to the physical landscape than by sensory disturbances. The construction of buildings, roads, compressor stations and oil wells on the landscape changes land-cover type, vegetation height and density, presence of perches and amount of edge habitat. These alterations to the landscape could affect prey abundance, prey availability, perch availability and predation risk. It is likely a combination of these landscape changes that is influencing owl nocturnal space use.

We suggest that the greatest influence on owl nocturnal space use from alterations to land cover resulted from changes to prey habitats and populations. Small mammals depend on vegetation for cover and food, without which their populations cannot persist. Although artificial sound and light can influence prey abundance and availability (Francis et al. 2011, Gaston et al. 2013), changes to the vegeta- tion from construction of human features on the landscape probably has a much larger impact on prey populations than noise or light (Andrén 1994, Sauvajot et al. 1998, Mortelliti et al. 2009). Most roads in the Canadian grasslands follow the 1 mile $(\sim 1.6 \mathrm{~km})$ section lines originally laid out by the Dominion Land Survey of Canada in the late 1800s. Agricultural and industrial access roads reach deep inside those square-mile sections, leaving little of the landscape that is $<400 \mathrm{~m}$ from the nearest road and, therefore, almost all land is influenced by proximity to this human footprint. Construction of any road removes vegetation and typically changes adjacent vegetation type and height, resulting in widespread changes to grassland vegetation alongside roads and across the landscape (e.g. Wellicome et al. 2014). Ditches are associated with many roads, and vegetation grows taller and more dense in ditches because of greater local moisture levels, thus supporting greater small mammal populations (Poulin 2003). Direct removal and alteration of vegetation has a greater effect on small mammal populations, and thus space use of burrowing owls while hunting, than do effects from sensory disturbance.

If burrowing owl nocturnal space use was influenced by artificial sound, it would most likely be high frequency sounds, because they have the greatest 
potential to mask sounds made by prey (Miller 1978, Schomer \& Beck 2010). Sound in the $2.5 \mathrm{kHz}$ onethird octave band could only be potentially detected by owls within $3.2 \%$ of the home range, and sound in frequencies above $2.5 \mathrm{kHz}$ could be heard in smaller percentages of their home range. During dawn and dusk, the majority (slightly more than half) of the owls avoided areas with greater sound levels in high frequencies, but selection coefficients indicated that some individuals were attracted to these areas. Even if owls had shown strong avoidance of sounds in high frequencies, the impact to their foraging areas would have been negligible because the amount of area where owls could hear high frequency sounds was small.

The small number of owls that showed strong (significant) attraction to areas with higher sound levels were more influenced by distance to the infrastructure producing the sound. The sound modelling we conducted is very accurate and gives the ability to detect subtle impacts to owl nocturnal space use, but due to the nature of sound propagation and attenuation, there still remains a correlation between distance to sound-producing structures and sound levels. This correlation may explain why half of the owls showed selection for areas with higher sound levels, as the structures themselves may have had some attribute (i.e. perches) that owls selected. Alternatively, it is possible that burrowing owls rely more on visual detection of prey when hunting in areas with greater sound levels and are able to exploit prey that are less able to hear predators, thereby increasing owl hunting efficiency. It is more likely that owls are attracted to other characteristics, particular to the developments that are producing these sounds, rather than the higher sound levels. There are a number of features other than sound associated with sound sources that are more likely to be attracting owls. There are typically other structures near the sound sources (e.g. fences) that do not produce sound that could be used as perches, which are important features for burrowing owls (Sissons 2003, Scobie et al. 2014). In addition, gravel roads are constructed to access oil wells and compressor stations, many of which have ditches that likely have high abundances of small mammals (Adams \& Geis 1983, SabinoMarques \& Mira 2011, Ruiz-Capillas et al. 2013).

Sound in the middle frequencies $(1.25$ and $1.6 \mathrm{kHz})$ can be heard by burrowing owls farthest from the source, compared to either higher or lower frequencies. Anthropogenic sound in mid to low frequencies may not significantly affect an owl's ability to detect prey, but could affect its ability to attract a mate or effectively communicate warnings to mates or young. The primary song of the male burrowing owl that is used in pair formation and territory defense is comprised mostly of sound in low frequencies, $\leq 1.3 \mathrm{kHz}$ (Martin 1973). Warning calls given by adult burrowing owls also consist mostly of low frequency sounds, not exceeding $2.5 \mathrm{kHz}$ except when the highest degree of threat is being communicated (Martin 1973).

There is weak evidence that owls are influenced by artificial sound and light while foraging at night, but those effects are small when compared to the influence of physical changes to the landscape. Changes to prey abundance and/or availability and corresponding owl nocturnal space use likely explain why owls were most influenced by landscape changes from human development rather than by the sensory disturbances associated with human developments. Although owl nocturnal space use was least influenced by sensory disturbances, these effects should be considered, together with the effects from physical landscape changes, when determining effective habitat loss or degradation from development. While habitat loss is the greatest threat to terrestrial species (Wilcove et al. 1998, Sala et al. 2000), the extent to which ecosystems are impacted by artificial sound and light is becoming more clear (Francis \& Barber 2013, Gaston et al. 2013) and needs to be considered when assessing the total effect of human development on species.

Acknowledgements. We thank all organizations that provided financial or logistical support to this research, including Agriculture and Agri-Food Canada; Alberta Environment and Parks; Alberta North American Waterfowl Management Plan; Alberta Sport, Recreation, Parks and Wildlife Foundation; the Canadian Association of Petroleum Producers; Canadian Land Reclamation Association; Canadian Natural Resources Ltd.; Canadian Wildlife Service (Prairie and Northern Region); Cenovus Energy; ConocoPhillips Canada; Department of National Defence (Suffield); Environment Canada's Interdepartmental Recovery Fund; Husky Energy; Natural Sciences and Engineering Research Council of Canada; Nexen Inc.; PennWest Energy; and Saskatchewan Fish and Wildlife Development Fund. We are also very grateful to all of the landholders who granted us access to their land and to the field staff who assisted with data collection.

\section{LITERATURE CITED}

Abramsky Z, Rosenzweig ML, Belmaker J, Bar A (2004) The impact of long-term continuous risk of predation on two species of gerbils. Can J Zool 82:464-474

Adams LW, Geis AD (1983) Effects of roads on small mammals. J Appl Ecol 20:403-415

Aldridge CL, Boyce MS (2007) Linking occurrence and fit- 
ness to persistence: habitat-based approach for endangered greater sage-grouse. Ecol Appl 17:508-526

Andrén H (1994) Effects of habitat fragmentation on birds and mammals in landscapes with different proportions of suitable habitat: a review. Oikos 71:355-366

Barber JR, Crooks KR, Fristrup KM (2010) The costs of chronic noise exposure for terrestrial organisms. Trends Ecol Evol 25:180-189

Barnum SA, Manville CJ, Tester JR, Carmen WJ (1992) Path selection by Peromyscus leucopus in the presence and absence of vegetative cover. J Mammal 73:797-801

Besnard F, Hamet JF, Lelong J, Le Duc E, Furst N, Doisy S, Dutilleux G (2009) Road noise prediction. 1. Calculating sound emissions from road traffic. SETRA, Sourdun

Beyer HL (2012) Geospatial modelling environment. www. spatialecology.com/gme/gmedownload.htm

> Bird BL, Branch LC, Miller DL (2004) Effects of coastal lighting on foraging behavior of beach mice. Conserv Biol 18: 1435-1439

BirdLife International (2012) Athene cunicularia. The IUCN Red List of Threatened Species 2012: e.T2268953A4040 8155. http://dx.doi.org/10.2305/IUCN.UK.2012-1.RLTS. T22689353A40408155.en (accessed 18 Sep 2016)

Blickley JL, Blackwood D, Patricelli GL (2012) Experimental evidence for the effects of chronic anthropogenic noise on abundance of greater sage-grouse at leks. Conserv Biol 26:461-471

Bloom PH (1987) Capturing and handling raptors. In: Giron Pendleton BA, Millsap BA, Cline KW, Bird DM (eds) Raptor management techniques manual. National Wildlife Federation Scientific and Technical Series. National Wildlife Federation, Washington, DC, p 99-123

> Brittan-Powell EF, Dooling RJ, Gleich O (2002) Auditory brainstem responses in adult budgerigars (Melopsittacus undulatus). J Acoust Soc Am 112:999-1008

Brittan-Powell EF, Lohr B, Hahn DC, Dooling RJ (2005) Auditory brainstem responses in the eastern screech owl: an estimate of auditory thresholds. J Acoust Soc Am 118: 314-321

Brooks TM, Mittermeier RA, Mittermeier CG, da Fonseca GAB and others (2002) Habitat loss and extinction in the hotspots of biodiversity. Conserv Biol 16:909-923

Brumm H (2004) The impact of environmental noise on song amplitude in a territorial bird. J Anim Ecol 73:434-440

Burnham KP, Anderson DR (2002) Model selection and multimodel inference: a practical information-theoretic approach. Springer-Verlag, New York, NY

> Chubbs TE, Keith LB, Mahoney SP, McGrath MJ (1993) Responses of woodland caribou (Rangifer tarandus caribou) to clear cutting in east central Newfoundland. Can J Zool 71:487-493

- Clarke JA (1983) Moonlight's influence on predator/prey interactions between short-eared owls (Asio flammeus) and deermice (Peromyscus maniculatus). Behav Ecol Sociobiol 13:205-209

> Daly M, Behrends PR, Wilson MI, Jacobs LF (1992) Behavioral modulation of predation risk: moonlight avoidance and crepuscular compensation in a nocturnal desert rodent, Dipodomys merriami. Anim Behav 44:1-9

$>$ Delgado JD, Arevalo JR, Fernandez-Palacios JM (2008) Bird communities in two oceanic island forests fragmented by roads on Tenerife, Canary Islands. Ostrich 79:219-226

> Dice LR (1945) Minimum intensities of illumination under which owls can find dead prey by sight. Am Nat 79: 385-416
Environment Canada (2012) Recovery strategy for the burrowing owl (Athene cunicularia) in Canada. Government of Canada, Ottawa

Federal Highway Administration (2013) Traffic monitoring guide, US Department of Transportation, Washington, DC

Fischer J, Lindenmayer DB (2007) Landscape modification and habitat fragmentation: a synthesis. Glob Ecol Biogeogr 16:265-280

Fisher RJ, Wellicome TI, Bayne EM, Poulin RG, Todd LD, Ford AT (2015) Extreme precipitation reduces reproductive output of an endangered raptor. J Appl Ecol 52: 1500-1508

Francis CD, Barber JR (2013) A framework for understanding noise impacts on wildlife: an urgent conservation priority. Front Ecol Environ 11:305-313

Francis CD, Paritsis J, Ortega CP, Cruz A (2011) Landscape patterns of avian habitat use and nest success are affected by chronic gas well compressor noise. Landsc Ecol 26:1269-1280

Frye GG, Jageman HR (2012) Post-fledging ecology of northern pygmy owls in the Rocky Mountains. Wilson J Ornithol 124:199-207

- Gaston KJ, Bennie J, Davies TW, Hopkins J (2013) The ecological impacts of nighttime light pollution: a mechanistic appraisal. Biol Rev Camb Philos Soc 88:912-927

Gauthier DA, Wiken EB (2003) Monitoring the conservation of grassland habitats, Prairie Ecozone, Canada. Environ Monit Assess 88:343-364

Glenn EM, Hansen MC, Anthony RG (2004) Spotted owl home-range and habitat use in young forests of western Oregon. J Wildl Manag 68:33-50

> Goerlitz HR, Greif S, Siemers BM (2008) Cues for acoustic detection of prey: insect rustling sounds and the influence of walking substrate. J Exp Biol 211:2799-2806

> Hübner M, Wiegrebe L (2003) The effect of temporal structure on rustling-sound detection in the gleaning bat, Megaderma lyra. J Comp Physiol A Neuroethol Sens Neural Behav Physiol 189:337-346

IHS Energy (2011a) Canada gas plant data. IHS Energy (Canada), Calgary

IHS Energy (2011b) Canada transportation infrastructure data. IHS Energy (Canada), Calgary

IHS Energy (2011c) Canada well data. IHS Energy (Canada), Calgary

ISO (International Organization for Standardization) (1993) ISO 9613-1. Acoustics - attenuation of sound during propagation outdoors. Part 1: Calculation of the absorption of sound by the atmosphere. ISO, Geneva

ISO (1994) ISO 8297. Acoustics - determination of sound power levels of multisource industrial plants for evaluation of sound pressure levels in the environment-engineering method. ISO, Geneva

ISO (1996) ISO 9613-2. Acoustics - attenuation of sound during propagation outdoors. Part 2: General method of calculation. ISO, Geneva

ISO (2010) ISO 3746. Acoustics - determination of sound power levels of noise sources using sound pressure. Survey method using an enveloping measurement surface over a reflecting plane. ISO, Geneva

Jiang GS, Ma JZ, Zhang MH, Stott P (2010) Multi-scale foraging habitat use and interactions by sympatric cervids in northeastern China. J Wildl Manag 74: 678-689

Kaufman DW (1974) Differential predation on active and inactive prey by owls. Auk 91:172-173 
Kaufman DW, Kaufman GA (1982) Effect of moonlight on activity and microhabitat use by Ord's kangaroo rat (Dipodomys ordii). J Mammal 63:309-312

Knudsen EI, Konishi M (1979) Mechanisms of sound localization in the barn owl (Tyto alba). J Comp Physiol 133: 13-21

Kotler BP, Brown JS, Hasson O (1991) Factors affecting gerbil foraging behavior and rates of owl predation. Ecology 72:2249-2260

> Lockard RB, Owings DH (1974) Moon-related surface activity of bannertail (Dipodomys spectabilis) and fresno (D. nitratoides) kangaroo rats. Anim Behav 22:262-273

> Longcore T, Rich C (2004) Ecological light pollution. Front Ecol Environ 2:191-198

Longcore T, Rich C (2006) Ecological consequences of artificial night lighting. Island Press, Washington, DC

Martin DJ (1973) A spectrographic analysis of burrowing owl vocalizations. Auk 90:564-578

Miller LN (1978) Sound levels of rain and wind in the trees. Noise Control Eng J 11:101-109

Mortelliti A, Sanzo GS, Boitani L (2009) Species' surrogacy for conservation planning: caveats from comparing the response of three arboreal rodents to habitat loss and fragmentation. Biodivers Conserv 18:1131-1145

Natural Resources Canada (2000) Canadian digital elevation data, level 1: Digital elevation models (cded1). Natural Resources Canada, Ottawa

> Neumann W, Ericsson G, Dettki H, Radeloff VC (2013) Behavioural response to infrastructure of wildlife adapted to natural disturbances. Landsc Urban Plan 114:9-27

Nielsen SE, Cranston J, Stenhouse G (2009) Identification of priority areas for grizzly bear conservation and recovery in Alberta, Canada. J Conserv Plann 5:38-60

Pater LL, Grubb TG, Delaney DK (2009) Recommendations for improved assessment of noise impacts on wildlife. J Wildl Manag 73:788-795

Payne RS (1971) Acoustic location of prey by barn owls (Tyto alba). J Exp Biol 54:535-573

Penteriani V, Kuparinen A, Del Mar Delgado M, Lourenço R, Campioni L (2011) Individual status, foraging effort and need for conspicuousness shape behavioural responses of a predator to moon phases. Anim Behav 82:413-420

Poulin RG (2003) Relationships between burrowing owls (Athene cunicularia), small mammals, and agriculture. PhD dissertation, University of Regina, Regina

> Poulin RG, Todd LD (2006) Sex and nest stage differences in the circadian foraging behaviors of nesting burrowing owls. Condor 108:856-864

Quinn GP, Keough MJ (2002) Experimental design and data analysis for biologists. Cambridge University Press, Cambridge

Roche BE, Schulte-Hostedde AI, Brooks RJ (1999) Route choice by deer mice (Peromyscus maniculatus): reducing the risk of auditory detection by predators. Am Midl Nat 142:194-197

> Rockhill AP, DePerno CS, Powell RA (2013) The effect of illumination and time of day on movements of bobcats (Lynx rufus). PLOS ONE 8:e69213

Rotics S, Dayan T, Kronfeld-Schor N (2011) Effect of artificial night lighting on temporally partitioned spiny mice. J Mammal 92:159-168

Ruiz-Capillas P, Mata C, Malo JE (2013) Road verges are refuges for small mammal populations in extensively managed Mediterranean landscapes. Biol Conserv 158: 223-229
Sabino-Marques H, Mira A (2011) Living on the verge: Are roads a more suitable refuge for small mammals than streams in Mediterranean pastureland? Ecol Res 26: $277-287$

Sala OE, Chapin FS III, Armesto JJ, Berlow E and others (2000) Biodiversity - global biodiversity scenarios for the year 2100. Science 287:1770-1774

Sauvajot R, Buechner M, Kamradt D, Schonewald C (1998) Patterns of human disturbance and response by small mammals and birds in chaparral near urban development. Urban Ecosyst 2:279-297

> Schaub A, Ostwald J, Siemers BM (2008) Foraging bats avoid noise. J Exp Biol 211:3174-3180

- Schomer P, Beck G (2010) Wind-induced pseudo-noise and leaf-rustle noise. Noise Control Eng J 58:121-131

Scobie C, Bayne E, Wellicome T (2014) Influence of anthropogenic features and traffic disturbance on burrowing owl diurnal roosting behavior. Endang Species Res 24: 73-83

Siemers BM, Schaub A (2011) Hunting at the highway: traffic noise reduces foraging efficiency in acoustic predators. Proc R Soc Lond B Biol Sci 278:1646-1652

Singheiser M, Plachta DTT, Brill S, Bremen P, van der Willigen RF, Wagner H (2010) Target-approaching behavior of barn owls (Tyto alba): influence of sound frequency. J Comp Physiol A Neuroethol Sens Neural Behav Physiol 196:227-240

Sissons RA (2003) Food and habitat selection of male burrowing owls (Athene cunicularia) on southern Alberta grasslands. MSc thesis, University of Alberta, Edmonton

Statistics Canada (2012) Census profile by population centres. 2011 census. Government of Canada, Ottawa

Summers PD, Cunnington GM, Fahrig L (2011) Are the negative effects of roads on breeding birds caused by traffic noise? J Appl Ecol 48:1527-1534

Titulaer M, Spoelstra K, Lange CYMJG, Visser ME (2012) Activity patterns during food provisioning are affected by artificial light in free living great tits (Parus major). PLOS ONE 7:e37377

> Volman SF, Konishi M (1990) Comparative physiology of sound localization in four species of owls. Brain Behav Evol 36:196-215

Wellicome TI, Haug EA (1995) Updated report on the status of the burrowing owl (Speotyto cunicularia) in Canada. Committee on the Status of Endangered Wildlife in Canada, Ottawa

> Wellicome TI, Kardynal KJ, Franken RJ, Gillies CS (2014) Off-road sampling reveals a different grassland bird community than roadside sampling: implications for survey design and estimates to guide conservation. Avian Conserv Ecol 9:4

Wilcove DS, Rothstein D, Dubow J, Phillips A, Losos E (1998) Quantifying threats to imperiled species in the United States. Bioscience 48:607-615

Winchell CS (1999) An efficient technique to capture complete broods of burrowing owls. Wildl Soc Bull 27: 193-196

Wolfe JL, Summerlin CT (1989) The influence of lunar light on nocturnal activity of the old-field mouse. Anim Behav $37: 410-414$

Zárybnická M, Korpimäki E, Griesser M (2012) Dark or short nights: differential latitudinal constraints in nestling provisioning patterns of a nocturnally hunting bird species. PLOS ONE 7:e36932 